\title{
Dopamine Inhibits Mitral/Tufted $\rightarrow$ Granule Cell Synapses in the Frog Olfactory Bulb
}

\author{
Ian G. Davison, Jamie D. Boyd, and Kerry R. Delaney \\ Department of Biological Sciences, Simon Fraser University, Burnaby, British Columbia, Canada V5A 1S6
}

Synaptic interactions between the dendrites of mitral/tufted (MT) and granule cells (GCs) in the olfactory bulb are important for the determination of spatiotemporal firing patterns of MTs, which form an odor representation passed to higher brain centers. These synapses are subject to modulation from several sources originating both within and outside the bulb. We show that dopamine, presumably released by TH-positive local interneurons, reduces synaptic transmission from MTs to GCs. MT neurons express D2-like receptors (D2Rs), and both dopamine and the D2 agonist quinpirole decrease EPSC amplitude at the MT $\rightarrow$ GC synapse. D2R activation also increases paired pulse facilitation and decreases the frequency of action potential-independent spontaneous miniature EPSCs in GCs, consistent with an effect on MT glutamate release downstream from Ca ${ }^{2+}$ influx. Analysis of spike-evoked $\mathrm{Ca}^{2+}$ transients in MT lateral dendrites additionally shows that quinpirole reduces $\mathrm{Ca}^{2+}$ influx preferentially at distal locations, possibly by reducing dendritic excitability via increased transient $\mathrm{K}^{+}$channel availability. When the $\mathrm{OB}$ is activated physiologically by using odor stimuli, blocking D2Rs increases the power of $\mathrm{GABA}_{\mathrm{A}}$-dependent oscillations in the local field potential. This demonstrates a functional role for the dopaminergic circuit during normal odor-evoked responses and for the modulation of dendritic release and excitability in neuronal circuit function. Regulation of spike invasion of lateral dendrites by transient $\mathrm{K}^{+}$currents also may provide a mechanism for local outputs of MTs to be controlled dynamically via other neuromodulators or by postsynaptic potentials.

Key words: reciprocal synapse; mitral cell; lateral dendrite; feedback inhibition; D2; Rana pipiens

\section{Introduction}

The olfactory bulb $(\mathrm{OB})$ is responsible for the initial representation of odor information in the CNS. It receives inputs from populations of olfactory receptor neurons (ORNs), which are translated into distributed output patterns encoded in the firing of mitral/tufted cells (MTs). Although MT sensory inputs initially are determined by the topography of axonal projections of different receptor subtypes onto the glomerular layer (Buck, 2000), olfactory processing also relies on local inhibitory circuits. Mammalian periglomerular neurons, which release GABA and dopamine, attenuate inputs from ORN terminals (Wachowiak and Cohen, 1999; Aroniadou-Anderjaska et al., 2000; PalouzierPaulignan et al., 2002). $\mathrm{GABA}_{\mathrm{A}}$-dependent inhibition from granule cells (GCs) onto MTs also may play an important role in determining MT outputs. IPSPs and suppression of spiking are prominent features of MT responses to electrical and odor stimulation (Nowycky et al., 1981; Hamilton and Kauer, 1989), and localized $\mathrm{GABA}_{\mathrm{A}}$ blockade decreases MT tuning specificity (Yokoi et al., 1995). Lateral inhibition is proposed to enhance

Received June 2, 2004; revised July 19, 2004; accepted July 20, 2004.

This work was supported by Canadian Institutes of Health Research MOP14455 (K.R.D., I.G.D.), Natural Sciences and Engineering Research Council (NSERC) Canada RGPIN121698 (K.R.D.), Michael Smith Foundation for Health Research Career Investigator award (K.R.D.), and NSERC postgraduate scholarship (I.G.D.). We thank Dr. Tim Murphy for his generous sharing of equipment, facilities, and advice; Drs. Joanne Matsubara and Diane Finegood for the kind use of their microscopes and cameras; and Dr. Alan Gelperin for comments on this manuscript.

Correspondence should be addressed to lan Davison, Department of Neurobiology, Box 3209, Duke University Medical Center, Durham, NC 27710. E-mail: idavison@neuro.duke.edu.

DOI:10.1523/JNEUROSCI.2138-04.2004

Copyright $\odot 2004$ Society for Neuroscience $\quad$ 0270-6474/04/248057-11\$15.00/0 contrast within odor-evoked global activity patterns (Sachse and Galizia, 2002), and electrophysiology and imaging studies suggest that activated glomeruli produce an inhibitory surround (Luo and Katz, 2001; Aungst et al., 2003). Behaviorally, blocking $\mathrm{GABA}_{\mathrm{A}}$-dependent feedback in the honeybee antennal lobe produces deficits in odor discrimination (Stopfer et al., 1997). Changes in GC feedback also are linked to plasticity and learning. Noradrenaline released from locus coeruleus projections decreases feedback inhibition onto MTs (Jahr and Nicoll, 1982; Trombley, 1992; Czesnik et al., 2003), an effect believed to be important for long-term changes in both the main and accessory OB (Wilson and Sullivan, 1991; Kaba et al., 1994; Sullivan et al., 2000; Rumsey et al., 2001).

Determining how GC feedback inhibition affects the flow of information through the $\mathrm{OB}$ is important for understanding olfactory processing. An unusual feature of GCs is that they receive the majority of their synaptic input from dendritic rather than axonal release sites. Although dendritic glutamate release from MTs normally is supported by robust action potential invasion of their lateral dendrites, backpropagation can be modulated or eliminated by factors such as local inhibition (Lowe, 2002; Xiong and Chen, 2002). Christie and Westbrook (2003) found that A-type $\mathrm{K}^{+}$channels attenuate action potential amplitude in MT lateral dendrites as in other neuronal types (Hoffman et al., 1997). This may allow spike amplitude to be regulated dynamically by changes in membrane potential (Migliore et al., 1999; Watanabe et al., 2002) or by neuromodulators (Tsubokawa and Ross, 1997; Hoffman and Johnston, 1999). Here we find that 
dopamine (DA), presumably released by tyrosine hydroxylasepositive local interneurons that project within the mitral and plexiform layers in the frog (Boyd and Delaney, 2002), reduces $\mathrm{GABA}_{\mathrm{A}}$-dependent inhibition in the OB. DA decreases excitation of GCs via presynaptic effects on MTs, including direct inhibition of the release apparatus and reduced $\mathrm{Ca}^{2+}$ influx at distal sites on lateral dendrites that may result from decreased spike backpropagation. Pharmacological manipulation of dopamine D2 receptor activity also alters odor-evoked population responses, suggesting that local dopaminergic modulation normally contributes to ongoing odor processing.

\section{Materials and Methods}

Animals. Experiments were performed on olfactory bulbs from adult male Rana pipiens between 2 and 3.5 inches in length, obtained from Charles D. Sullivan (Nashville, TN). Frogs were maintained in a cooled environment on a $12 \mathrm{hr}$ light/dark cycle and fed with flies or crickets. Frogs were kept at room temperature for 1 week before experiments. Animals were maintained and killed in accordance with standards set by the Canadian Council on Animal Care and the Simon Fraser University Animal Care Committee.

Histology and immunohistochemistry. Frogs were anesthetized by immersion in $0.2 \%$ MS222 and perfused with saline, followed by $4 \%$ paraformaldehyde in PBS. Brains were immersion-fixed in the same fixative overnight; then they were embedded in $10 \%$ agarose and sectioned horizontally at $100 \mu \mathrm{m}$ with a vibrating microtome. Sections were incubated for $\sim 48 \mathrm{hr}$ in primary antibody solution containing $100 \mathrm{~mm}$ PBS, $1 \% \mathrm{w} / \mathrm{v}$ Triton X-100, 1\% normal goat serum (Vector Laboratories, Burlingame, $\mathrm{CA}$ ), and rabbit anti- $\alpha$-D2 receptor primary antibody (Ab; Chemicon, Temecula, CA) at dilutions of 1:250, 1:500, or 1:1000 at $4^{\circ} \mathrm{C}$. Sections then were rinsed three times in PBS and incubated for $2 \mathrm{hr}$ in biotinylated goat anti-rabbit $\mathrm{Ab}$ (1:200; room temperature). Slices again were rinsed three times in PBS, incubated overnight in standard ABC solution (Vector Laboratories), rinsed three times in TBS, and developed by using a standard DAB reaction procedure (reaction solution, $17 \mathrm{ml}$ of TBS, 0.91 $\mathrm{ml}$ of $1 \mathrm{~m}$ imidazole, $5 \mathrm{mg}$ of diaminobenzidine, $0.18 \mathrm{gm}$ of nickel ammonium sulfate, and $70 \mu \mathrm{l}$ of $0.1 \% \mathrm{H}_{2} \mathrm{O}_{2}$ ) (Tago et al., 1986).

For some slices, a double-labeling procedure was used in which MT axons were backfilled with biocytin through localized injections to the lateral olfactory tract. These cells were developed with standard ABC methods as above, resulting in a brown reaction product. In these experiments, gold-conjugated $2^{\circ}$ antibodies (1:200; Jackson ImmunoResearch, West Grove, PA) were used in place of a biotinylated label for separation of the receptor and backlabeling signals. The gold-conjugated Abs were developed by using a silver intensification procedure (IntenSe LE; Amersham Biosciences, Piscataway, NJ). Bright-field images of immunostained sections were taken on a Nikon Optiphot microscope with a Nikon Coolpix 995 digital camera or on an Olympus BX40 microscope with a Roper Scientific, Photometrics CoolSnap digital camera (Tucson, AZ). To measure optical density, we compared raw images with no saturated pixels with images of a series of neutral density filters of known transmittance captured with the same camera settings. A custom procedure in IgorPro (WaveMetrics; Lake Oswego, OR) was used to calculate average optical density in regions of interest drawn around the cell bodies of every backfilled cell (306 in total) in images collected at $40 \times$ magnification.

Electrophysiological recording. Local field potential and whole-cell patch recordings were made from a frog OB preparation (Delaney and Hall, 1996). Frogs were cryoanesthetized to full torpor by slow cooling to ice-bath temperature and were decapitated. The nose, olfactory epithelium, and OBs were dissected away, attached by the olfactory nerves. The two OB hemispheres were separated longitudinally with a razor blade, giving more ready access of patch pipettes to neuronal somata. Tissue was maintained at $19-22^{\circ} \mathrm{C}$ by perfusion with ACSF containing (in mM) 72 $\mathrm{NaCl}, 2 \mathrm{KCl}, 26 \mathrm{NaHCO}_{3}, 1.6 \mathrm{NaH}_{2} \mathrm{PO}_{4}, 1.5 \mathrm{MgSO}_{4}, 2 \mathrm{CaCl}_{2}$, and 10 glucose, continuously bubbled with $95 \% \mathrm{O}_{2} / 5 \% \mathrm{CO}_{2}$. For experiments with odor stimulation, the nose was maintained in a separate, dry chamber, isolated from the OB by a layer of petroleum jelly around the olfac- tory nerves. For other experiments, the olfactory nerves were cut at their point of entry through the cribriform plate.

Odor-evoked responses were elicited by injection of a small puff of saturated vapor from one of three different odorants ( $n$-butanol, limonene, or methyl salicylate; Sigma, St. Louis, MO) into a steady stream of filtered, moisturized air directed onto the olfactory epithelium through the internal nares. Final dilutions at the sensory epithelium were brief pulses $(30-150 \mathrm{msec})$ estimated to be $0.5-3 \%$ of saturated vapor, adjusted so that sensory-evoked responses were $25-40 \%$ of maximal size. Electrical stimulation was accomplished by using a twisted pair of 0.125 $\mu \mathrm{m}$ enamel-coated silver wires placed on the olfactory nerve and lateral olfactory tract. Local field potentials were recorded by using lowresistance (2-4 $\mathrm{M} \Omega$ ) glass micropipettes containing artificial CSF (ACSF) solution inserted to a depth of $250-500 \mu \mathrm{m}$ into the $\mathrm{OB}$ and bandpass-filtered between $0.3 \mathrm{~Hz}$ and $1 \mathrm{kHz}$. Because the frog $\mathrm{OB}$ is not highly laminated, the local field potential (LFP) is relatively stereotyped over this depth. Odor-evoked LFP oscillations used to calculate power spectra additionally were filtered digitally between 1 and $40 \mathrm{~Hz}$. Wholecell recordings were made with either an Axopatch 200B (Axon Instruments, Union City, CA) or a PC-505 amplifier (Warner Instruments, Hamden, CT), using pipettes with resistances of 4-12 M $\Omega$. Internal solutions for current clamp contained (in $\mathrm{mm}$ ) $85 \mathrm{~K}$-gluconate, $4 \mathrm{KCl}, 4$ $\mathrm{NaCl}, 5$ D-glucose, 5 HEPES, $2 \mathrm{MgCl}_{2}, 0.5$ glutathione, $1 \mathrm{Na}$-ATP, 0.3 Na-GTP, and 1 EGTA. Voltage-clamp solutions contained (in mM) 78 $\mathrm{CsMeSO}_{4}$, 2.5 QX-314, 7 TEA, 5 D-glucose, 5 HEPES, $2 \mathrm{MgCl}_{2}$, $2 \mathrm{Na}$-ATP, 1 EGTA, 0.5 glutathione, and $0.3 \mathrm{Na}$-GTP. Most internal solutions contained $0.2 \%$ biocytin for cell identification after recording. Voltage-clamp data were low-pass-filtered at 5 or $2 \mathrm{kHz}$, and traces were digitized at 10 or $3.3 \mathrm{kHz}$ on a PC, using pClamp 7.0 (Axon Instruments), or on a Macintosh, using Superscope II software (GW Instruments, Somerville, MA).

Imaging. For recording dendritic $\mathrm{Ca}^{2+}$ transients, we recorded MT cells in current-clamp mode, filled with $250 \mu \mathrm{M}$ fluo- 4 included in the patch pipette. Action potentials were evoked by short current injections (8-30 msec, $0.4-3.0 \mathrm{nA})$, and transients were measured in lateral dendrites at different distances from the soma via line scans. Two-photon scanning was performed by using a modified confocal scan head equipped with a non-descanned detector (Bio-Rad MRC600, Coherent Verdi 5W Ar pump laser, and Mira 900 Ti-Sapphire pulsed laser) and a custom-built system (Coherent Verdi $10 \mathrm{~W}$ and Mira 900, IGOR-based drivers and acquisition, and Cambridge Technologies galvanometers). Four to eight scans were averaged for each distance and drug treatment for comparison. Cellular morphology was reconstructed from a $z$-series of images obtained after completion of electrophysiological recordings to determine the distance of the optical recording site from the soma.

To test for D2-mediated effects on olfactory nerve inputs, we labeled receptor terminals via the olfactory nerve, using suction electrodes filled with either calcium green-1 dextran (3000 MW) or fluo-4 dextran $(10,000 \mathrm{MW})$ at $5-10 \% \mathrm{w} / \mathrm{v}$ in a $0.1 \%$ Triton X-100 solution in $\mathrm{dH}_{2} \mathrm{O} . \mathrm{Ca}^{2+}$ transients evoked by nerve stimulation were recorded with a photomultiplier tube (PMT; H5873, Hamamatsu, Bridgewater, NJ) attached to a custom-built wide-field epifluorescence microscope, with the excitation illumination aperture limited to illuminate $\sim 5-20$ filled glomeruli.

\section{Results}

\section{MT neurons express D2-like receptors}

Autoradiography has shown that D2-like receptors (D2Rs) in frog are localized mainly in the MT layer and, unlike in mammals, generally are absent from the glomerular layer (Duchamp-Viret et al., 1997). We found that a polyclonal antibody against D2Rs labeled many neurons in the frog $\mathrm{OB}$, with staining concentrated in the MT layer (Fig. 1A, low-power view of a horizontal OB section). Figure $1 B$ shows a higher-magnification view confirming that labeled cells possess an MT-like morphology, with arrows indicating cells with clearly stained dendrites as well as somata within the plane of section. None of the stained processes was seen to possess spines, arguing that D2Rs are not expressed in the processes of granule cells. To confirm that the labeled neurons were in fact MTs, we made biocytin injections into the lateral 

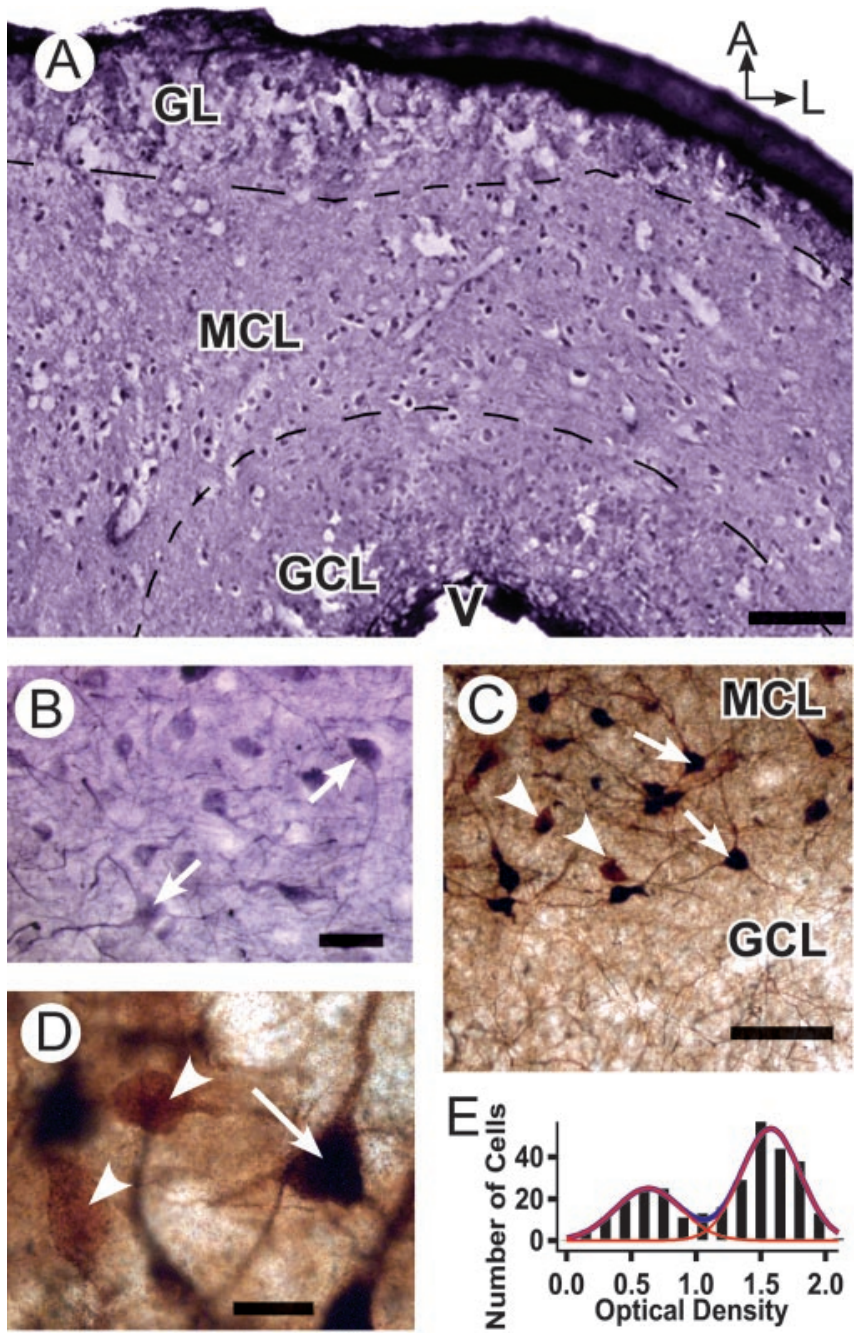

Figure 1. D2Rs are expressed on frog mitral neurons. A, Low-power view of a horizontal olfactory bulb section stained with an anti-D2R antibody and visualized with a nickel-enhanced peroxidase reaction. Labeled cells are visible primarily in the mitral cell layer, the borders of which are indicated by dashed lines. B, Higher-power view of mitral cell layer showing labeled cells and processes. Arrows mark cells showing well labeled dendrites in the plane of section. $C$, Double-labeling experiment. Backfilling of the lateral olfactory tract with biocytin resulted in labeling of the majority of MTs, which were visualized with immunoperoxidase, resulting in a brown reaction product. D2R immunoreactivity was visualized with a gold-conjugated secondary antibody and a silver intensification procedure, producing black staining. Although not all backfilled cells stained for D2R (arrowheads), all D2R-positive cells were backfilled (arrows). The granule cell layer contains mitral cell dendrites stained by D2R immunostaining and/or backfilling, but no D2R-positive cell bodies. D, High-power view of backfilled mitral cells that are either D2R-positive (arrow) or D2R-negative (arrowheads). The black silver precipitate of D2R staining is very dense in the soma of D2R-positive cells, masking the brown immunoperoxidase reaction product of backfilled biocytin, but is less dense in the dendrites, allowing the brown reaction product to show and identify these cells as double-labeled. $E$, Histogram of calibrated optical density measurements from the somata of backlabeled cells, with two peaks corresponding to D2R-negative (left) and D2R-positive (right) neurons. Approximately $65 \%$ of neurons are D2Rpositive, calculated by integration of the area under Gaussian fits to each distribution (red; blue line shows the sum of the two fits). A, Anterior; L, lateral; $\mathrm{GL}$, glomerular layer; $\mathrm{MCL}$, mitral cell layer; GCL, granule cell layer; V, ventricle. Scale bars: $A, 100 \mu \mathrm{m} ; B, 25 \mu \mathrm{m} ; C, 50 \mu \mathrm{m} ; D$ (for $D$, E), $10 \mu \mathrm{m}$.

olfactory tract, resulting in the backfilling of a large number of these cells. In regions of the bulb in which MT labeling was most complete, all D2-positive cells were backfilled, confirming that the cells that express D2 receptors are MTs (Fig. 1C). Only approximately two-thirds of the backfilled cells were D2-positive, however, suggesting heterogeneity in D2R expression (Fig. $1 D$, arrows and arrowheads indicate D2-positive and D2-negative cells, respectively). No obvious pattern was apparent with regard to the location of D2-positive or D2-negative MTs; the two classes of cells intermingled both tangentially and radially. Although D2-positive and D2-negative cells easily could be distinguished visually, densitometric analysis of backfilled MTs in the double-labeled tissue was used to look for subclasses of MTs with different levels of D2 staining. A histogram of optical density (Fig. $1 E$ ) was well fit by a sum of two Gaussians, consistent with the presence of only two classes of MTs, D2-negative and D2positive. Integration of the area under each of the two Gaussians contributing to the curve gave a proportion of 1:1.9 D2-negative to D2-positive MTs, in agreement with the value obtained by visual inspection.

\section{Dopamine and quinpirole inhibit lateral olfactory tract-evoked GC field EPSCs}

The presence of D2Rs on frog MTs indicates that DA release is likely to have effects on the membrane properties or synaptic output of these cells. To explore this possibility, we used stimulation of the lateral olfactory tract (LOT) to activate the MT $\rightarrow$ GC synapse monosynaptically, and we used LFPs measured from the plexiform/GC layers of the OB to monitor GC population activity. Action potentials in MTs, stimulated antidromically, produce glutamate release onto GCs and subsequent $\mathrm{GABA}_{\mathrm{A}}$ feedback onto MTs (Nowycky et al., 1981). This was reflected in field potential recordings from the $\mathrm{OB}$, which exhibit an initial shortlatency positive phase (P1) corresponding to antidromic spike generation in MTs (Fig. 2A), blocked by TTX, but not by ionotropic glutamate and GABA receptor antagonists. This is followed by a negative phase (N1) corresponding to the GC EPSC (blocked by a combination of DNQX, APV, and 7-Clkynurenate). The third, positive, component (P2) reflects $\mathrm{GABA}_{\mathrm{A}}$ feedback onto MTs and is sensitive to bicuculline. Pharmacological evaluation of the LFP components also was confirmed by cell-attached and whole-cell recordings from MTs and GCs, which showed the correspondence between spikes in each cell type with the evoked LFP components (data not shown).

Bath application of DA to the OB caused a dose-dependent reduction in the amplitude of the LOT-evoked GC EPSC, with an $\mathrm{EC}_{50}$ value of $10 \mu \mathrm{M}$ (Fig. $2 \mathrm{~B}-\mathrm{E}$ ). Results from several preparations were equivalent whether measurements of EPSC peak amplitude or slope were used. Extracellular perfusion with $50 \mu \mathrm{M}$ DA resulted in a decrease in the GC (N1) component to $62 \pm$ $20 \%$ of control $(p<0.02 ; n=5)$ that was reversible on washout or with additional application of the D2-like antagonist sulpiride $(10 \mu \mathrm{M})$ (Fig. 2E). The D1-like agonist SKF38393 had no effect at concentrations up to $50 \mu \mathrm{M}$ (Fig. $2 B)(p>0.2 ; n=6)$. The D2-like agonist quinpirole mimicked the effect of DA on the GC EPSC, with an $\mathrm{EC}_{50}$ value of $0.3 \mu \mathrm{M}$ (Fig. $2 B-D$ ) and at a concentration of $5 \mu \mathrm{M}$ decreased the GC component to $59 \pm 8 \%$ of control (Fig. $2 E)(p<0.001 ; n=6)$, similar to the reduction seen with DA. This effect again was antagonized by sulpiride. Thus activation of D2Rs on MTs appears to have a strong effect on the strength of the $\mathrm{MT} \rightarrow \mathrm{GC}$ synapse.

\section{Quinpirole reduces whole-cell EPSCs in GCs}

Whole-cell recordings were made from GCs to confirm this idea and test it in more detail. A combination of electrophysiological and anatomical criteria was used to distinguish between MT and GCs in blind recordings (Hall and Delaney, 2002). Initial electrode placement was guided by visualization of the laminar structure of the OB. Electrical stimulation of the LOT evoked distinct 

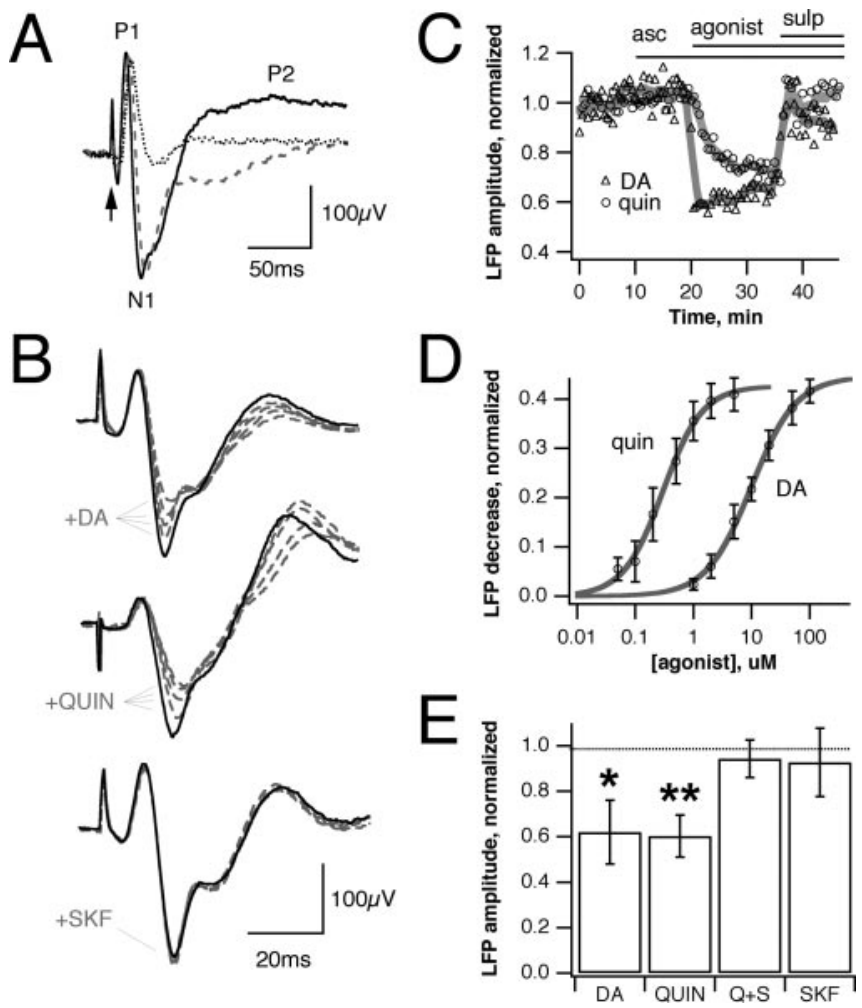

Figure 2. Dopamine and the D2 agonist quinpirole decrease $\mathrm{GC}$ population EPSCs in OB local field potentials. A, Pharmacological characterization of the field signal evoked by LOT stimulation (arrow). Feedback inhibition, generating the late positive component (P2), is blocked by bicuculline (gray). The negative GC EPSC component (N1) is blocked by CNQX, APV, and 7-Clkynurenate, leaving only a TTX-sensitive MT population spike (P1, dotted). B, Both dopamine and quinpirole produce a dose-dependent reduction in the GC EPSC, whereas the D1 agonist SKF38393 has no effect (black solid line, control; gray dashed line, increasing agonist concentration). C, Stable reduction in EPSC by dopamine (triangles) and quinpirole (circles) occurs quickly on agonist wash in and is reversed by the D2 antagonist sulpiride. Na-ascorbate (10 $\mu \mathrm{M})$, added to prevent the oxidation of DA, has no effect. $D$, Concentration dependence of EPSC reduction; $\mathrm{EC}_{50}$ values are $10 \mu \mathrm{m}$ for dopamine and $0.3 \mu \mathrm{m}$ for quinpirole. E, Dopamine $(50 \mu \mathrm{m})$ reduces the $\mathrm{GC}$ EPSC to $62 \pm 20 \%$ of control $(p<0.02 ; n=5)$, whereas $5 \mu \mathrm{m}$ quinpirole produces a similar decrease to $59 \pm 8 \%(p<0.001 ; n=6)$ that is reversed by sulpiride. SKF38393 $(50 \mu \mathrm{M})$ has no significant effect $(93 \pm 15 \% ; p>0.2 ; n=6)$. Bars in $D$ and $E$ show mean $\pm \mathrm{SE}_{;} ; p<0.05 ;{ }^{* *} p<0.005$.

synaptic responses in both cell types. GC EPSCs reversed at $\sim 0$ $\mathrm{mV}$ and were blocked by a combination of $10 \mu \mathrm{M}$ DNQX and 100 $\mu \mathrm{M}$ APV/10 $\mu \mathrm{M}$ 7-Cl-kynurenate. MTs responded to LOT stimulation with a barrage of inhibitory postsynaptic currents that were bicuculline-sensitive, reversed at approximately $-50 \mathrm{mV}$ (predicted $\mathrm{Cl}^{-}$reversal, $-47 \mathrm{mV}$ ), and lasted for several hundred milliseconds. IPSCs sometimes were preceded by short-latency $(\sim 5-10 \mathrm{msec})$ antidromic spike currents. In current-clamp mode the GCs responded to prolonged current injection with accommodating spike trains, with membrane voltage eventually reaching a stable plateau, whereas MTs fired a continuous train of action potentials (APs), as previously described (Hall and Delaney, 2001). Cells were filled frequently with biocytin and processed for visualization to confirm previous electrophysiological identification. In $\mathrm{Ca}^{2+}$ imaging experiments the recordings were made under visual control, and morphology could be seen with fluorescence; thus cell type could be confirmed directly.

Voltage-clamp recordings from individual GCs confirmed that the decrease in GC field EPSC after quinpirole application is attributable to reduced synaptic excitation. Consistent with LFP measurements, the application of $5 \mu \mathrm{M}$ quinpirole caused a sig- nificant reduction in the amplitude of evoked synaptic currents in GCs (to $65 \pm 14 \%$ of control; $n=6$; $p<0.01$ ), which was antagonized by $10 \mu \mathrm{M}$ sulpiride (Fig. $3 A$ ). The intracellularly recorded GC EPSC, like the field EPSC, was unaffected by the D1 agonist SKF38393 (data not shown).

Changes in paired pulse facilitation suggest that decreased EPSCs result from changes in MT glutamate release rather than decreased sensitivity of GCs. LOT shocks delivered at intervals of 125-200 msec, approximating the $\sim 8-12$ Hz odor-evoked oscillation frequency in the frog $\mathrm{OB}$, typically produced a slight decrease in the size of the second response. As well as reducing the amplitude of the first response, quinpirole increased the paired pulse ratio (EPSC2/EPSC1) from $0.79 \pm 15$ to $1.27 \pm 0.27 \%$ ( $p<$ $0.05 ; n=5)$ (Fig. $3 B$ ), consistent with decreased initial transmitter release but augmented facilitation in the presence of D2 activation.

The frequency of miniature EPSCs (mEPSCs) recorded from GCs in the presence of TTX $(1 \mu \mathrm{M})$ also suggests that D2 activation results in a reduction of MT glutamate release. GCs, which in the intact $\mathrm{OB}$ receive inputs from a large number of MTs, still displayed frequent spontaneous excitatory synaptic inputs $(\sim 3-30 \mathrm{~Hz})$ (Fig. 3C) in TTX. Quinpirole (5 $\mu \mathrm{M})$ consistently shifted the mEPSC frequency distribution toward longer interevent intervals (Fig. 3D) $(p<0.00005$ in 5 of 5 cells; Kolmogorov-Smirnov test). Quinpirole also produced smaller and inconsistent effects on the mEPSC size distribution $(p<0.05$ for 4 of 5 cells), suggesting that there also may be some change in postsynaptic sensitivity. However, this effect was much less pronounced and was not significant when average amplitudes for each cell were pooled (Fig. $2 E$ ) (amplitude $90 \pm 10 \%$ of control; $p>0.05$ ). Pooled mEPSC frequency, on the other hand, was reduced to $56 \pm 6 \%$ of control (Fig. $2 D)(p<0.05)$, consistent with a primarily presynaptic action of DA on MTs.

\section{Quinpirole reduces feedback IPSCs in MT cells}

Because GCs make reciprocal synapses with MTs, any mechanism that reduces synaptic excitation of GCs also will be expected to reduce the IPSCs that subsequently are produced in MTs. MTs were depolarized to $-10 \mathrm{mV}$ to isolate IPSCs as outward currents, and LOT stimulation was used to activate circuit-wide feedback inhibition by generating spikes in a large population of MTs. IPSCs recorded from voltage-clamped MTs were particularly long lasting, as has been noted for $\mathrm{GABA}_{\mathrm{A}}$-dependent inhibition in previous studies (Fig. 4A) (Isaacson and Strowbridge, 1998; Schoppa et al., 1998), and reversed at approximately $-50 \mathrm{mV}$ (Fig. $4 B$ ). Bicuculline-sensitive feedback/feedforward IPSCs generated in MTs via LOT stimulation were reduced to $59 \pm 12 \%$ of control by $5 \mu \mathrm{M}$ quinpirole, and this reduction was reversed by sulpiride (Fig. $4 C, D)(p<0.05 ; n=4)$.

\section{D2 activation reduces action potential propagation in MT lateral dendrites}

Although the reduction in mEPSC frequency in GCs suggests a direct effect on transmitter release itself, D2 activation also could affect evoked release in other ways. Transmitter release from MT lateral dendrites is believed to be attributable to AP propagation throughout these structures, generating $\mathrm{Ca}^{2+}$ influx via highvoltage-activated $\mathrm{Ca}^{2+}$ channels (Isaacson and Strowbridge, 1998). Any reduction in either global $\mathrm{Ca}^{2+}$ influx or in the degree of spike invasion then will cause a decrease in glutamate release (Lowe, 2002; Xiong and Chen, 2002). To evaluate these possibilities, we recorded spike-dependent $\mathrm{Ca}^{2+}$ transients from lateral dendrites of MTs, which have been used as a measure of dendritic 
A
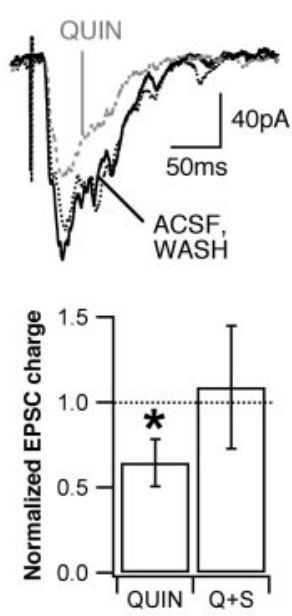

C
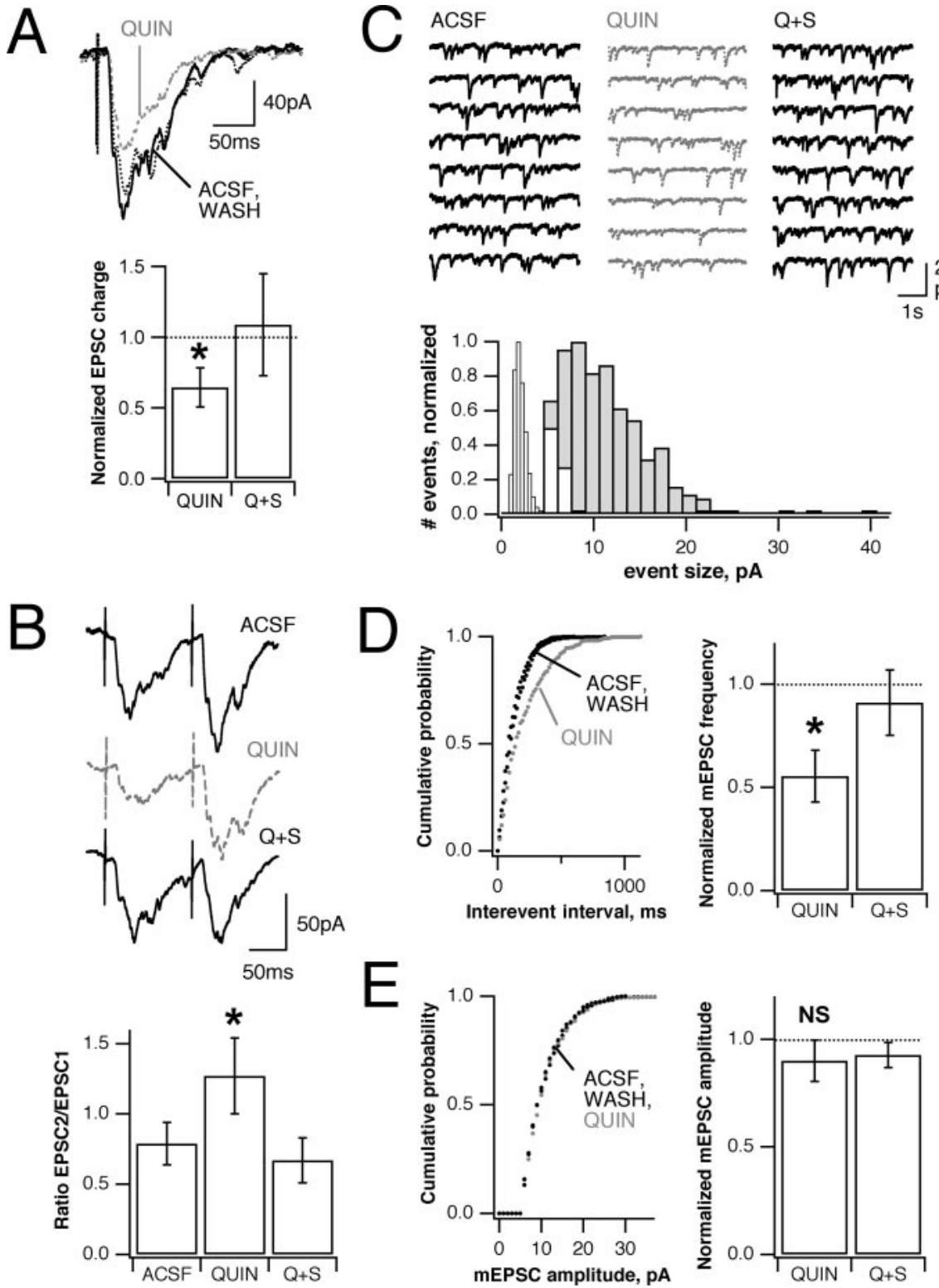

Figure 3. Whole-cell GC EPSCs also are reduced by D2 receptor activation. $A$, Quinpirole $(5 \mu \mathrm{m})$ decreases LOT-evoked EPSCs in $\mathrm{GCS}$, voltage-clamped at $-70 \mathrm{mV}$, to $65 \pm 14 \%$ of control $(n=6 ; p<0.01$; solid black line, control; gray dashed line, quinpirole; gray dotted line, sulpiride). $B$, Paired pulse facilitation (EPSC2/EPSC1) also is increased from $0.79 \pm 0.15$ to $1.27 \pm 0.27$ ( $p<$ $0.05 ; n=5$; top, control; middle, quinpirole; bottom, quinpirole plus sulpiride). C, Activity-independent spontaneous mEPSC frequency is lowered by quinpirole. Left (black), control; middle (gray), quinpirole; right (black), quinpirole plus sulpiride. A histogram of mEPSC size distribution (gray, control) shows that most events are excitatory, with few inhibitory events remaining after ionotropic glutamate receptor block (white). Minimum event size was set at $5 \mathrm{pA}$; bins on the left indicate current noise distribution after blockade of all synaptic events (inward events only). D, E, Cumulative frequency plots for mEPSC inter-event interval and amplitude in an individual $\mathrm{GC}$ show an effect on frequency $(D)$, but not on size $(E)$. Pooled average mEPSC frequency and amplitude across all cells (bars) show that the primary effect is on frequency $(56 \pm 6 \%$ of control; $p<0.05)$ rather than on amplitude $(90 \pm 10 \% ; p>0.05)$. Bars show mean $\pm \mathrm{SE} ;{ }^{*} p<0.05$.

spike invasion both in vitro and in vivo (Spruston et al., 1995; Svoboda et al., 1997; Xiong and Chen, 2002). Short current pulses (15-60 msec, $0.4-3.0 \mathrm{nA}$ ), individually or in trains of three to four at $10 \mathrm{~Hz}$, were used to drive APs in somatic current-clamp recordings of individual MTs filled with 200-300 $\mu \mathrm{M}$ fluo-4. MT lateral dendrites project extensively, and fluorescence transients could be recorded at distances $>700 \mu \mathrm{m}$ from the soma with a two-photon laser microscope in line-scan mode (Fig. 5A). APs driven by somatic current injection produced fast $\mathrm{Ca}^{2+}$ transients at all locations in the lateral dendrite, suggesting that spikes

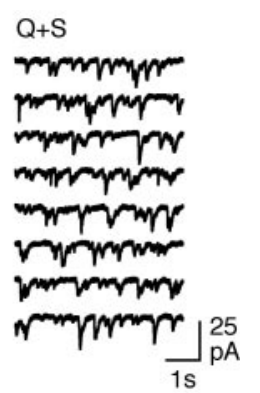

invaded their full extent. Transients had amplitudes of $\sim 60-120 \% \Delta F / F$ and were sensitive to TTX and $\mathrm{Cd}^{2+}$; their amplitude was not activity-dependent (third spike in the train, $102 \pm 4 \%$ of first; $p>0.5 ; n=10$ ) (data not shown). Accurate measurement of $\Delta F / F$ was difficult because of the low resting fluorescence of the dye, and absolute changes in fluorescence $(\Delta F)$ were used for additional quantification.

Some MTs (6 of 13) responded to bath application of $5 \mu \mathrm{M}$ quinpirole with a membrane hyperpolarization of 4-7 $\mathrm{mV}$, whereas others were unaffected, consistent with the presence of a subpopulation of D2-immunopositive MTs. AP-dependent $\mathrm{Ca}^{2+}$ transients were unchanged in cells displaying no shift in membrane potential (Fig. $5 C)(96 \pm 6 \% ; p>0.05 ; n=9)$, whereas transients often were reduced in cells demonstrating a hyperpolarizing response, and this reduction could be reversed by depolarizing current (Fig. 5A,C). The amount of reduction was correlated with the distance from the soma at which the measurement was made (Fig. 5C) (9.7\% reduction in amplitude/100 $\mu \mathrm{m}$ dendrite, slope significantly different from zero; $p<0.0005)$, indicating that APs were less effective in invading distal portions of the dendrites in the presence of quinpirole. This effect could be duplicated by hyperpolarizing the cells artificially with somatic current injection before spike generation (Fig. 5B,C) (slope, $-12.1 \% / 100 \mu \mathrm{m}$ dendrite; $p<0.01)$. Current injection hyperpolarized MTs by $20-30 \mathrm{mV}$, to compensate for electrotonic decay in extended MT lateral dendrites and to produce more robust and quantifiable changes in transient amplitude, and generated a larger change in $\mathrm{Ca}^{2+}$ influx than D2R activation. These observations are consistent with reduced spike invasion into MT lateral dendrites produced by $\mathrm{D} 2 \mathrm{R}$ activation in a hyperpolarization-dependent manner.

\section{A-type $\mathrm{K}^{+}$channels are expressed by MTs}

Transient $\mathrm{K}^{+}$channels are known to reduce AP backpropagation in the dendrites of hippocampal pyramidal cells, where their fast activation kinetics allow them to counteract depolarization because of voltage-gated $\mathrm{Na}^{+}$and $\mathrm{Ca}^{2+}$ channels and to dampen AP peaks (Johnston et al., 2000). Whole-cell voltage-clamp recordings from MTs, with $\mathrm{Na}^{+}$and $\mathrm{Ca}^{2+}$ currents eliminated by TTX/QX314 and $\mathrm{Ca}^{2+}$-free solution, respectively, revealed a fast-inactivating outward current sensitive to millimolar concentrations of 4-aminopyridine (4AP) (Fig. $6 \mathrm{~A}$, left). This current activates and inactivates at relatively hyperpolarized potentials (Fig. $6 A$, center, right panels) ( $V_{1 / 2}$ for inactivation, $-60 \mathrm{mV}$ ). The steepest portion of its inactivation curve coincides with typical MT resting membrane po- 


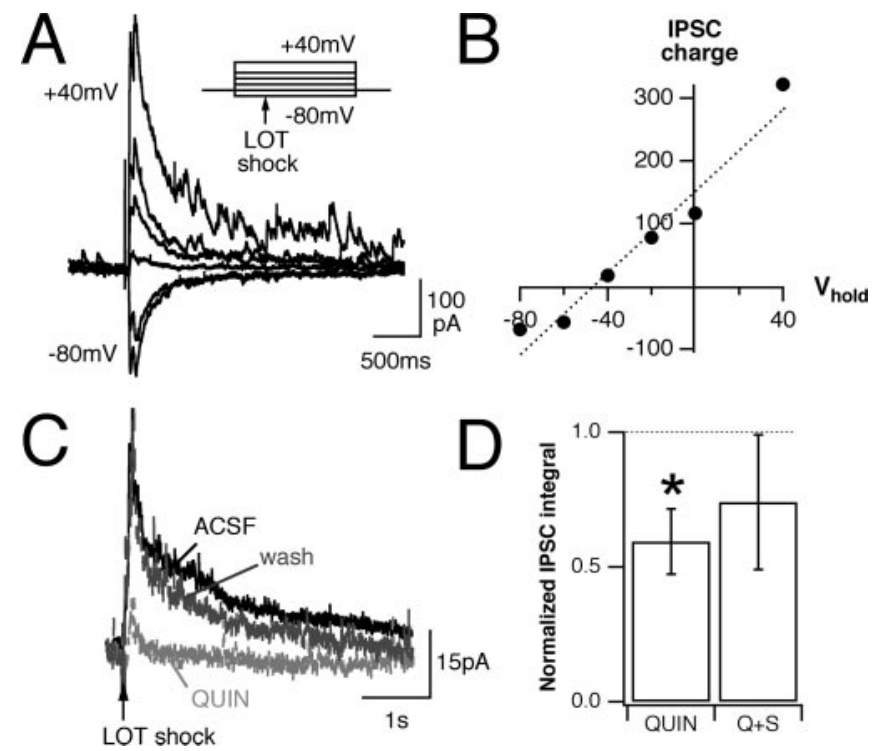

Figure 4. Quinpirole decreases feedback inhibition in MTs. A, LOT stimulation, activating a population of MTs and consequently producing network GC feedback, generates inhibitory synaptic currents measured in a MT neuron held at membrane potentials between -80 and $+40 \mathrm{mV}$. B, MT IPSCs (quantified by charge integral) reverse at approximately $-50 \mathrm{mV}$. C, Quinpirole reduces LOT-evoked IPSCs recorded from a MT neuron (black, control; gray, quinpirole). D, Bar graph showing pooled data. Quinpirole decreases integrated IPSC charge in MTs to $59 \pm 12 \%$ of control $(p<0.05 ; n=4)$. Bars show mean $\pm \mathrm{SE} ;{ }^{*} p<0.05$.

tentials (RMPs), suggesting that changes in polarization around rest could affect the availability of this current and, consequently, neuronal excitability. Consistent with this, somatic action potential waveforms recorded in current-clamp mode are sensitive to changes in MT membrane potential. Hyperpolarizing steps immediately preceding spike generation resulted in action potentials that were reduced in amplitude and repolarized more rapidly (Fig. $6 B$, left $)(p<0.001 ; n=6$ for both amplitude and repolarization). Perfusion with 3-5 mM 4-AP increased MT spike height and width and reduced repolarization slope but did not affect depolarization (Fig. 6B, center). 4-AP also eliminated the ability of hyperpolarizing presteps to alter AP shape (Fig. $6 \mathrm{~B}$, right; pooled results are summarized in $C$ ). This indicates that fast, transient $\mathrm{K}^{+}$currents are expressed by these cells and are capable of influencing their electrophysiological properties.

\section{4-AP prevents hyperpolarization-induced changes in dendritic $\mathrm{Ca}^{2+}$ transients}

If A-type $\mathrm{K}^{+}$currents mediate the reduction in dendritic $\mathrm{Ca}^{2+}$ transient amplitude, then blockade of these channels should eliminate the effects produced by hyperpolarization. Extracellular perfusion with 3-5 mM 4-AP increased the size of $\mathrm{Ca}^{2+}$ transients at all locations within lateral dendrites (Fig. 7A,B) $(201 \pm$ $58 \%$ of control; $p<0.01 ; n=6$ ), an effect that likely is caused by an increase in action potential width as well as an increase in effectiveness of invasion. While maintained in standard ACSF, the hyperpolarization of MTs reduced $\mathrm{Ca}^{2+}$ transient amplitude to $78 \pm 10 \%$ of control $(p<0.001 ; n=7)$. After treatment with 4 -AP, hyperpolarization no longer produced any change in transient amplitude (Fig. 7C) (98 $\pm 6 \%$ of control; $p>0.3 ; n=6)$. There was no significant trend in the increase produced by 4 -AP at different dendritic locations, suggesting that under our recording conditions the available $I_{\mathrm{A}}$ does not cause significant spike attenuation in the lateral dendrites (Fig. $7 B$ ) (slope not significantly different from $0 ; p>0.05$ ). These observations suggest that 4 -AP-
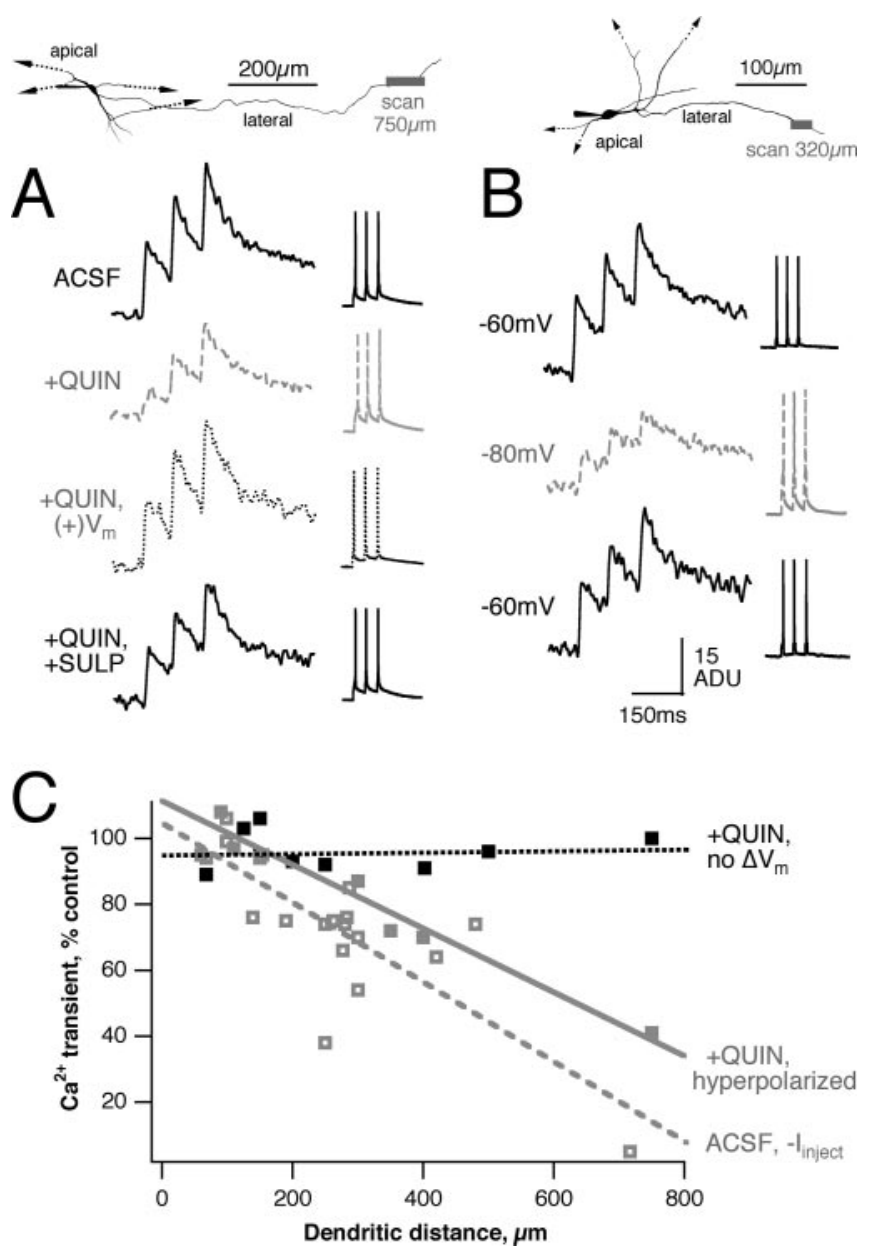

Figure 5. Changes in MT membrane potential result in reduced dendritic $\mathrm{Ca}^{2+}$ transients. $A$, In cases in which quinpirole hyperpolarized MT membrane potential, dendritic $\mathrm{Ca}^{2+}$ transients were decreased in amplitude (gray dashed line). Top, Reconstruction of neuron and recording location. Right, Action potentials generated by short current injections. Left, Resulting dendritic $\mathrm{Ca}^{2+}$ transients (average of 3 or more trials). Injection of depolarizing current, returning the cell to its original membrane potential, restores the transients (dotted lines, + QUIN, $+V_{\mathrm{m}}$ ). $B$, Hyperpolarizing MTs by direct current injection, in control ACSF, also reduces transient amplitude (dashed line). C, The degree of reduction in transient size depends both on hyperpolarization and on distance or recording location from the soma. In cases in which membrane potential remained constant, there was no significant decrease in transient amplitude (black filled squares). For neurons that were hyperpolarized by quinpirole (gray filled squares) or by somatic current injection (gray open squares), transients farther from the soma were reduced to a greater degree (quinpirole: $9.7 \%$ reduction in amplitude $/ 100 \mu \mathrm{m}$ dendrite, slope significantly different from zero, $p<0.0005$; hyperpolarizing current: slope $-12.1 \% / 100 \mu$ m dendrite, $p<0.01$ ).

sensitive $\mathrm{K}^{+}$currents are responsible for hyperpolarizationdependent changes in dendritic $\mathrm{Ca}^{2+}$ influx.

\section{Dopamine modulates odor-evoked OB responses}

A DA-induced change in odor-evoked $\mathrm{OB}$ responses potentially could reflect a change in ORN input to the $\mathrm{OB}$ as well as a change in the $\mathrm{MT} \rightarrow \mathrm{GC}$ reciprocal synapse. In mammalian systems DA has been shown to reduce synaptic transmission at the $\mathrm{ORN} \rightarrow$ MT synapse (Hsia et al., 1999). This effect is mediated by a reduction of $\mathrm{Ca}^{2+}$ influx in ORN terminals, as is another form of presynaptic inhibition at this synapse that is dependent on $\mathrm{GABA}_{\mathrm{B}}$ receptors (Wachowiak and Cohen, 1999). In frog ORN terminals filled with the fluorescent $\mathrm{Ca}^{2+}$ indicator calcium green-1 dextran, $5 \mu \mathrm{M}$ quinpirole produced neither a significant change in $\mathrm{Ca}^{2+}$ influx resulting from electrical stimulation of the 

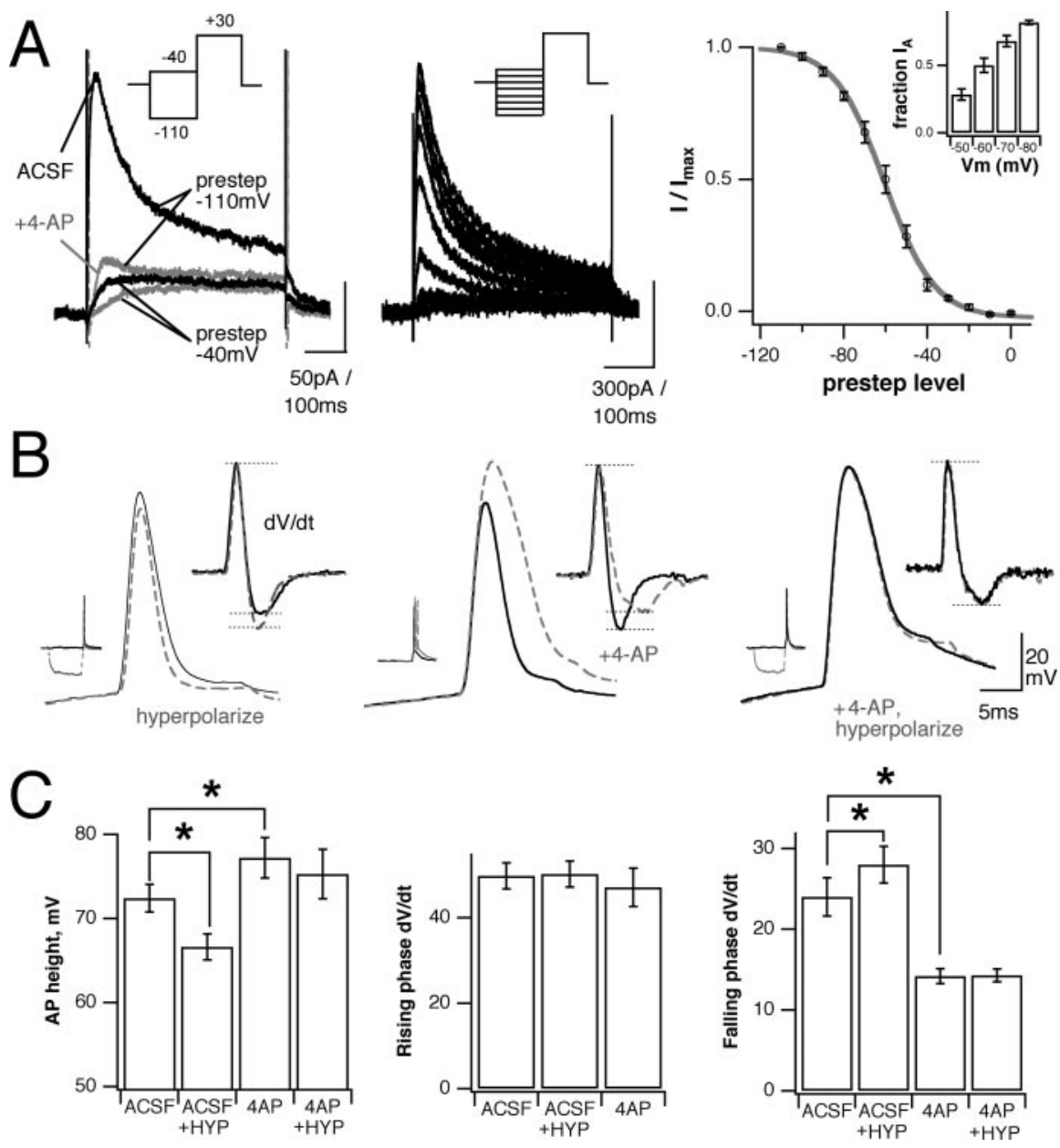

Figure 6. MTs express A-type $\mathrm{K}^{+}$currents that can modulate action potential waveform. $A$, Left, Voltage steps to $+30 \mathrm{mV}$ evoke a fast-activating, fast-inactivating outward current that is inactivated by a prestep to $40 \mathrm{mV}$ and that is blocked by $3-5 \mathrm{~mm}$ 4-AP (gray). Center, Family of inactivating currents generated by varying prestep potential, generated by digital subtraction of slow, noninactivating current. Right, Resulting inactivation curve for this current family; $50 \%$ inactivation is at $-60.5 \mathrm{mV}$. Inset, Fractional current available at membrane potentials close to MT resting $V_{\mathrm{m}} \cdot B$, Left, Hyperpolarizing presteps produce shorter and narrower APs recorded at the soma (solid black line, control; gray dashed line, hyperpolarized). Inset shows $d V / d t$, revealing that changes are the result of increased repolarization. Center, Blocking fast $\mathrm{K}^{+}$currents with 4-AP increases AP height and width by decreasing repolarization (inset, $d V / d t$ ). Right, After 4-AP application the hyperpolarizing presteps no longer affect AP shape. $C$, Summary of AP waveform results. In ACSF the hyperpolarization significantly reduces spike height and increases repolarization slope (left and right graphs, $p<0.001 ; n=18$ for both) but does not affect depolarization slope (middle graph, $p>0.2 ; n=18$ ). The 3-5 mm 4-AP increases spike height and repolarization at RMP ( $p<0.002$ and 0.005 , respectively; $n=8)$ but does not affect the rate of depolarization ( $p>0.05 ; n=6$ ). 4-AP also prevents the hyperpolarization-induced changes in AP height and repolarization ( $p>0.05$ and 0.5 , respectively; $n=6$ ). Bars show mean $\pm \mathrm{SE} ;{ }^{*} p<0.05$.

olfactory nerve $(\Delta F / F=12.5 \pm 2.5$ vs $12.3 \pm 2.5 \% ; p>0.5 ; n=$ 7 ) nor any change in paired pulse depression of influx (transient $2 /$ transient $1=0.56 \pm 0.16$ for both; $p>0.5 ; n=6$ ) (Fig. $8 A$ ). This observation, coupled with the lack of clear D2R labeling in the glomerular layer of the frog (Duchamp-Viret et al., 1997) and the robust effect of quinpirole on LOT-evoked field potentials and EPSCs at the same concentration, suggests that the majority of D2R-mediated effects on odor-evoked responses under these conditions can be attributed to the $\mathrm{MT} \rightarrow \mathrm{GC}$ synapse.

Although dopaminergic cells are present in the OB (Boyd and Delaney, 2002) and our data indicate that DA can modulate transmitter release within the bulb, it is not clear what role dopaminergic neurons play during an odor response. With the use of an in vitro preparation with the sensory epithelium maintained intact (Delaney and Hall, 1996), brief pulses of odorants (40-300 msec; $n$-butanol, limonene, or methyl salicylate) applied to the sensory epithelium produced an evoked oscillation in the LFP that lasted $\sim 2-3 \mathrm{sec}$ (Fig. $8 B$ ). This oscillation was correlated with periodic spiking in MTs alternating with synaptic $\mathrm{GABA}_{\mathrm{A}}$ feedback inhibition presumed to be received from GCs, because both GABAergic feedback and LFP oscillations are eliminated by $10 \mu \mathrm{M}$ bicuculline (Lagier et al., 2004) (data not shown).

Extracellular perfusion with $5 \mu \mathrm{M}$ sulpiride to block D2R activation caused an increase in the amplitude of the odorevoked oscillation, indicating that the endogenous dopaminergic system is activated within individual odor responses and influences the functioning of the olfactory circuit (Fig. $8 \mathrm{~B}$ ). This was analyzed further by calculating power spectra for each odor-evoked epoch of LFP oscillation. The power of the oscillations was centered at $\sim 6-9 \mathrm{~Hz}$, and the strength of the response in each condition (control or with drug application) was quantified as the area under the averaged power spectrum (average of 3-6 trials, digitally bandpass-filtered from 1.5 to $40 \mathrm{~Hz}$; areas calculated from the 2-20 Hz band containing $>90 \%$ of total power). Sulpiride produced a $229 \pm 45 \%$ increase in average integrated LFP power ( $p<0.05 ; n=6)$. Because the LFP is a population average, this could result from an increase in the overall extracellular current flow generating the LFP (i.e., an increase in inhibitory feedback), an increase in the degree of synchronization of these currents, or both. This effect was present regardless of whether higher cortical structures were intact, demonstrating that dopaminergic modulation results from systems intrinsic to the bulb.

Additional experiments suggest that the changes in LFP power produced by D2R agonists and antagonists result from altered $\mathrm{GABA}_{\mathrm{A}}$ feedback. Transient $\mathrm{K}^{+}$ currents act in the $\mathrm{OB}$ to reduce activation of the GC feedback circuit by counteracting fast excitation of GCs through non-NMDA glutamate receptors (Schoppa and Westbrook, 1999). Perfusion of the OB with $2.5 \mathrm{~mm} 4$-AP, increasing GC excitation and the degree of GABAergic feedback inhibition, mimicked the effect of sulpiride and produced an increase of $194 \pm 25 \%$ in the power of the LFP oscillation (Fig. $8 B)(p<$ $0.05 ; n=4)$. On the other hand, $5 \mu \mathrm{M}$ quinpirole, activating D2 receptors and decreasing synaptic inputs to GCs, gave a $47 \pm 1 \%$ decrease in LFP power $(p<0.0001 ; n=5)$. Again, this was mimicked by reducing the amount of feedback inhibition by partially blocking $\mathrm{GABA}_{\mathrm{A}}$ receptors with $3 \mu \mathrm{M}$ bicuculline $(73 \pm 5 \%$ decrease; $p<0.01 ; n=5)$. Thus changing the levels of $\mathrm{D} 2 \mathrm{R}$ activation and directly altering the level of feedback inhibition produce parallel changes in oscillatory odor-evoked LFPs in the OB.

Finally, activation of D2Rs also appears to regulate resting levels of $\mathrm{OB}$ activity. Besides reducing the power of odor-evoked 

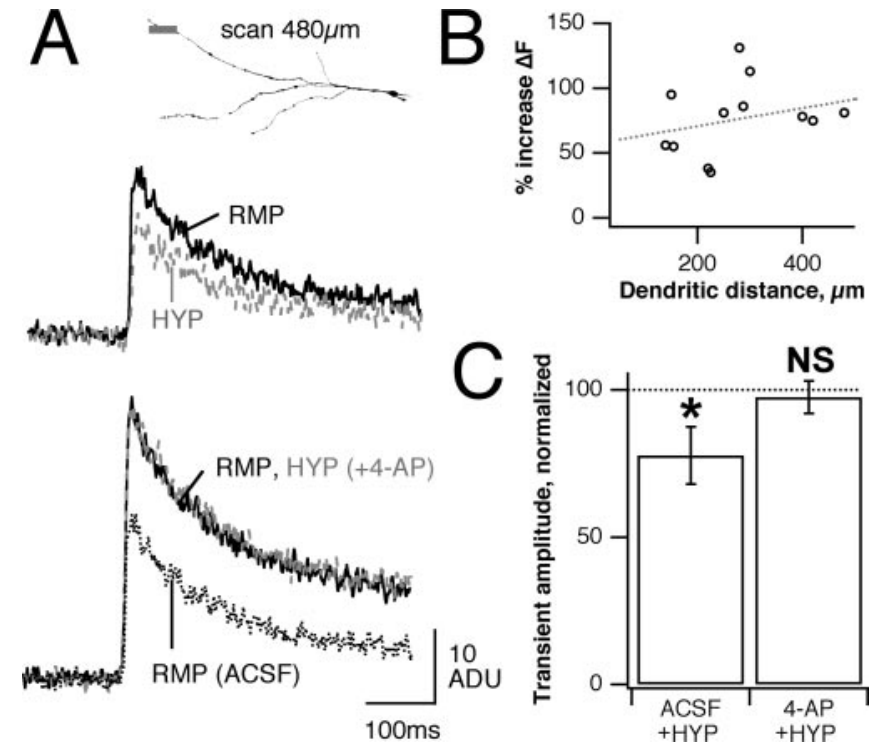

Figure 7. Block of fast $\mathrm{K}^{+}$currents eliminates changes in dendritic $\mathrm{Ca}^{2+}$ transient caused by hyperpolarization. $A$, Top, Control transients (solid black line) are reduced by a negative prestep (gray dashed line). Bottom, 4-AP increases transient size as compared with control (solid line vs dotted line) and prevents the ability of presteps to decrease transient amplitude. $B$, Increase in dendritic $\mathrm{Ca}^{2+}$ transient amplitude produced by 4-AP, plotted versus dendritic location; trend is not significant $(p>0.05)$. C, In ACSF the presteps reduce transients to $78 \pm$ $10 \%$ of control $(p<0.001 ; n=6)$ but have no effect in 4-AP $(98 \pm 6 \% ; p>0.3 ; n=6)$. Bars show mean $\pm \mathrm{SE} ;{ }^{*} p<0.05$.

oscillations, quinpirole also reduced LFP power under resting, unstimulated conditions (Fig. 8C) $(32 \pm 3 \% ; p<0.0001 ; n=5)$. Notably, blocking D2R activation with sulpiride greatly increased resting baseline LFP activity $(561 \pm 207 \%$ of control power; $p<$ $0.03 ; n=6$ ), suggesting that significant amounts of basal DA release occur on an ongoing basis in the $\mathrm{OB}$, where they reduce overall neuronal activity.

\section{Discussion}

Both experiments (Yokoi et al., 1995; Stopfer et al., 1997; MacLeod et al., 1998; Nusser et al., 2001; Sachse et al., 2002) and theory (Bazhenov et al., 2001) highlight the importance of inhibitory neuronal networks in olfactory circuit function. GABAergic inhibition in the vertebrate $\mathrm{OB}$ depends mainly on synaptic interactions between the dendrites of MTs and GCs and will be affected by changes in transmitter release and excitability within these neural populations. Using a combination of field potential measurements, whole-cell recording, and $\mathrm{Ca}^{2+}$ imaging, we demonstrate that activation of D2Rs on MTs in the frog OB reduces the strength of the MT $\rightarrow$ GC synapse and decreases feedback and feedforward inhibition received by MTs. Changes in mEPSC frequency in TTX suggest that this effect is mediated partly by reduced MT glutamate release independent of spikeevoked $\mathrm{Ca}^{2+}$ influx. D2R activation also decreases $\mathrm{Ca}^{2+}$ influx in MT distal lateral dendrites, the site of synapses onto GC spines, an effect that may result from decreased dendritic excitability produced by a transient $\mathrm{K}^{+}$current. During odor-evoked responses the blockade of D2 receptors increases inhibition-dependent field potential oscillations, suggesting that the dopaminergic system regulates the amount of inhibition generated as the OB processes physiologically relevant stimuli.

\section{Cellular effects of DA}

GABAergic inhibition has been suggested to augment the response properties of MTs (Yokoi et al., 1995) such that MT firing within a strongly activated glomerulus causes widespread GC activation and generates feedforward inhibition of MTs in more weakly activated glomeruli. Because MT lateral dendrites project extensively (Mori et al., 1983), they may be capable of generating widely distributed inhibition. The dual inhibitory effects on MT function described here have differing implications for GC network activity. Decreased MT glutamate release downstream of $\mathrm{Ca}^{2+}$ influx (Fig. 3C) should produce a uniform, global reduction of GC excitation and resulting inhibition. Decreased distal $\mathrm{Ca}^{2+}$ influx (Fig. 5C), alternatively, will decrease selectively the excitation of distant GCs and potentially change the spatial profile of inhibition generated by an active $\mathrm{OB}$ region (Xiong and Chen, 2002).

The relative contributions of these two mechanisms are not clear in these experiments. Reduced release probability independent of $\mathrm{Ca}^{2+}$ influx (Momiyama and Sim, 1996; Wu and Saggau, 1997) potentially could account for the entire decrease in evoked transmission ( $41 \pm 8$ and $35 \pm 14 \%$ reduction in population and whole-cell EPSCs, respectively, vs $44 \pm 6 \%$ reduction in mEPSC frequency). However, although reduced mEPSC frequency often correlates directly with a reduction in evoked release (Wu and Saggau, 1997), this is not always the case. At cerebellar synapses, although $\mathrm{GABA}_{\mathrm{B}}$ activation produces a marked $\mathrm{Ca}^{2+}$. independent decrease in mEPSC frequency, this accounts for only $10-30 \%$ of the total reduction of evoked transmission, with the remainder caused by additional downregulation of $\mathrm{Ca}^{2+}$ influx (Dittman and Regehr, 1996). In the OB the glutamate release likely is reduced both by $\mathrm{Ca}^{2+}$-independent mechanisms and by decreased dendritic spike invasion.

\section{Reduced $\mathrm{Ca}^{2+}$ influx in dendrites}

MT lateral dendrites are an important source of excitatory synaptic inputs to GCs, and reduced $\mathrm{Ca}^{2+}$ influx is predicted to decrease glutamate release from these compartments. Receptormediated presynaptic inhibition often acts via voltage-gated calcium channels (VGCCs) (Wu and Saggau, 1997; Wachowiak and Cohen, 1999), and the reduction seen here could be explained by preferential modulation of distal VGCCs. However, D2R activation reduced $\mathrm{Ca}^{2+}$ transients only in hyperpolarized MTs, and this decrease was reproduced by hyperpolarizing with current injection, which is not expected to inhibit VGCCs directly (Fig. $5 B, C)$. Although $\mathrm{D} 2 \mathrm{R}$ activation and direct hyperpolarization could act via different mechanisms, the reduction produced by D2Rs was reversed by depolarization (Fig. 5A). These data are consistent with indirect effects resulting from D2R-mediated hyperpolarization of MTs, perhaps generated by coupling to $\mathrm{K}^{+}$channels (Lacey et al., 1987; Kim et al., 1995; Kloppenburg et al., 1999).

One way of translating hyperpolarization into decreased $\mathrm{Ca}^{2+}$ influx is through transient $\mathrm{K}^{+}$currents, which affect dendritic excitability in several cell types (Hoffman et al., 1997; Christie and Westbrook, 2003; Goldberg et al., 2003). Although the difficulty in accurately controlling voltage in extended MT dendritic compartments likely introduces some inaccuracy in our measurements of kinetics and voltage dependence (Spruston et al., 1993), MTs clearly express a 4-AP-sensitive, fast-activating $\mathrm{K}^{+}$ current with properties consistent with those previously described for $I_{\mathrm{A}}$ (Huguenard et al., 1991; Hoffman et al., 1997; Christie and Westbrook, 2003). In MTs the A-current blockade increases spike-evoked $\mathrm{Ca}^{2+}$ transients preferentially in distal lateral dendrites, indicating that it can influence dendritic AP invasion (Christie and Westbrook, 2003). In pyramidal neurons the dendritic $I_{\mathrm{A}}$ produces strongly decremental AP backpropagation (Hoffman et al., 1997), and depolarizing inputs that inacti- 
A

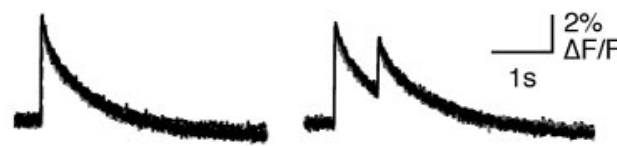

$\mathrm{B}$
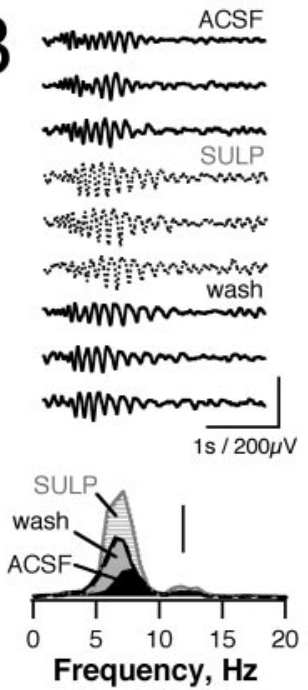

Frequency, $\mathrm{Hz}$
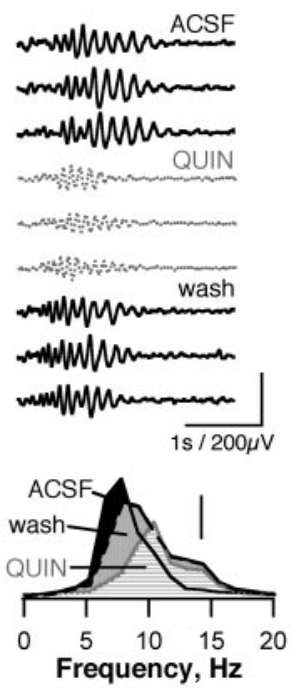

$\mathrm{C}$
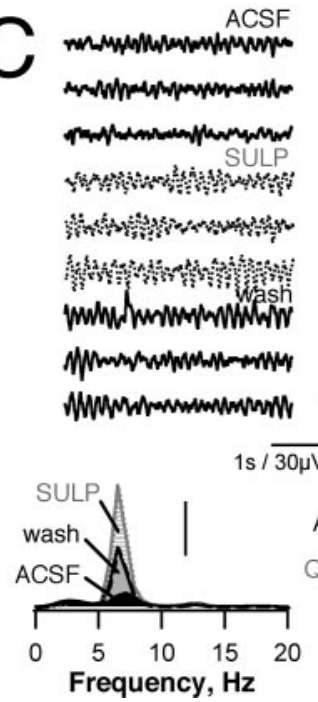

ACSF
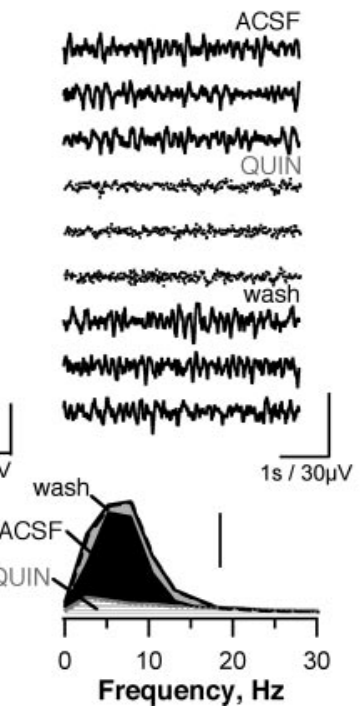
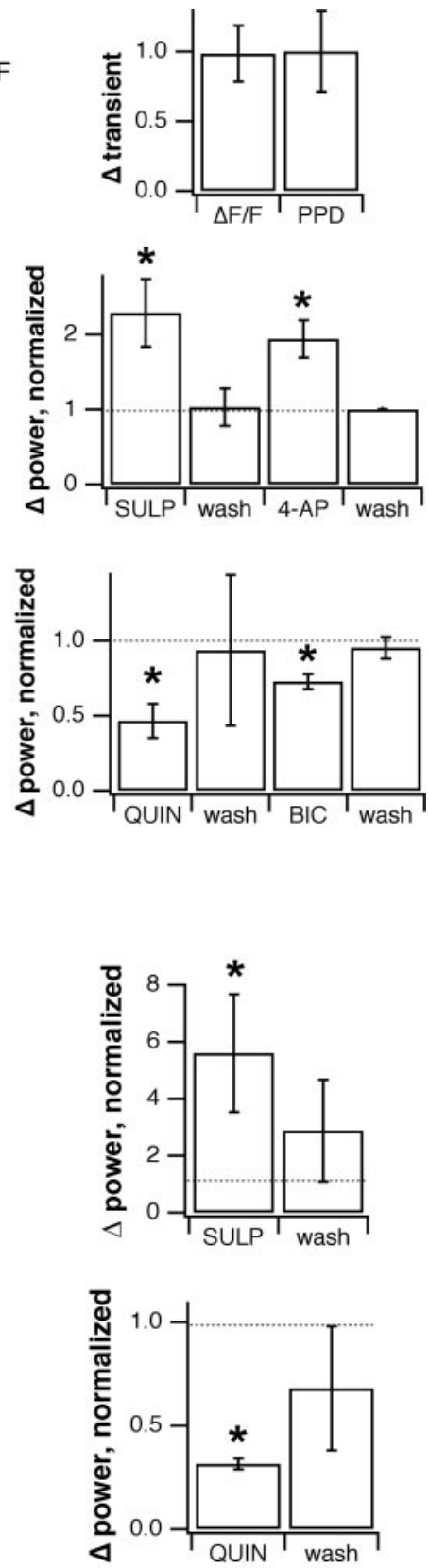

Figure 8. D2 receptor activation produces inhibition-dependent changes in olfactory bulb population activity. $A$, Quinpirole has no effect on either peak or paired pulse reduction in $\mathrm{Ca}^{2+}$ influx into olfactory receptor terminals in the glomerular layer ( $\triangle F / F, 12 \pm 2.5$ vs $12.3 \pm 2.5 \%$; PPD, $0.56 \pm 0.16 ; p>0.4$ for both cases; traces are overlaid). $B, 0$ odor-evoked, inhibitiondependent LFP oscillations are increased by block of D2 receptors (left) and decreased by D2R activation (right). Raw traces show three trials from each condition, with dotted lines showing drug trials. Bottom, Left, Power spectra averaged across all trials (solid black line, control; gray horizontal lines, drug treatment; gray fill, control). Right, Integrated power from 2 to $20 \mathrm{~Hz}$ pooled across several preparations. Sulpiride increases power $229 \pm 45 \%(p<0.05 ; n=6)$, an effect that is mimicked by 4-AP (194 $\pm 25 \%$; $p<0.05 ; n=4)$. Quinpirole decreases power to $47 \pm 11 \%(p<0.0001 ; n=5)$ as does $1-3 \mu$ m bicuculline $(73 \pm 5 \% ; p<$ $0.01 ; n=5)$. C, Resting activity also is increased by sulpiride ( $561 \pm 207 \%$ of control; $p<0.03 ; n=6$ ) and decreased by quinpirole ( $32 \pm 3 \%$ of control; $p<0.0001 ; n=5$; displayed as in $B$ ).

vate this current potentiate spike invasion (Migliore et al., 1999; Watanabe et al., 2002). In MTs, however, spike backpropagation in lateral dendrites is relatively effective (Lowe, 2002; Xiong and Chen, 2002; Christie and Westbrook, 2003; Debarbieux et al., 2003) (but see Margrie et al., 2001). Hyperpolarization then may reduce dendritic spike invasion via removal of tonic inactivation of $I_{\mathrm{A}}$, which is affected strongly by voltage charges around MT resting potential (Fig. $6 A$ ). Indeed, block of $I_{\mathrm{A}}$ eliminates the ability of hyperpolarization to reduce dendritic $\mathrm{Ca}^{2+}$ influx (Fig. 7). Although this was not measured directly, an additional possibility is that D2Rs potentially could alter activation or inactivation properties of this current via second messenger systems (Hoffman and Johnston, 1999; Kloppenburg et al., 1999).

A primarily hyperpolarization-dependent modulation of $I_{\mathrm{A}}$ fits well with the fact that synaptic inputs received by MT lateral dendrites are primarily inhibitory and can generate large IPSPs (Mori et al., 1981; Nowycky et al., 1981). Focally evoked GABAergic inputs strongly affect spikes in lateral dendrites (Lowe, 2002; Xiong and Chen, 2002), although this effect could be attributable to hyperpolarization, shunting, or both. In CA1 pyramidal cells distally evoked IPSPs also reduce action potential backpropagation (Tsubokawa and Ross, 1997). Although inactivation of $I_{\mathrm{A}}$ occurs quickly, which may allow it to be affected by synaptic events, its availability also will be altered by slower changes in membrane potential caused by neuromodulators such as seen here.

\section{D2 receptor localization in frog} and mammal

In mammalian systems D2 receptors and DA-immunoreactive interneurons are located primarily in the glomerular layer (Halasz et al., 1981; Kosaka et al., 1985; Coronas et al., 1997; Koster et al., 1999) where they reduce $\mathrm{Ca}^{2+}$ influx and transmitter release at ORN terminals (Hsia et al., 1999; Wachowiak and Cohen, 1999; Berkowicz and Trombley, 2000; Ennis et al., 2001). D2R labeling in the frog occurs in the MT and plexiform layers, with little signal in the glomerular layer (DuchampViret et al., 1997). Consistent with this receptor localization, dopaminergic interneurons in amphibians, fish, and reptiles also are located in deeper $\mathrm{OB}$ layers (Halasz et al., 1983; Alonso et al., 1989; Gonzalez and Smeets, 1991). Although some dopaminergic neurons in frogs extend processes into the glomerular layer, many arborize exclusively in the MT layer (Boyd and Delaney, 2002) where they could affect MT and GC dendrites. Consistent with this, we find that, in the frog, DA reduces transmission at the $\mathrm{MT} \rightarrow \mathrm{GC}$ synapse. DA also modulates glutamate release from MTs onto interneurons in cultured mammalian OB neurons, although this was attributed to VGCC downregulation (Davila et al., 2003).

\section{Modulation and odor-evoked responses}

Odor-evoked LFP oscillations in the antennal lobe and vertebrate $\mathrm{OB}$ are eliminated by pharmacological block of GABAergic feed- 
back, suggesting that they are dependent on inhibition (MacLeod and Laurent, 1996; Lagier et al., 2004). The strength of the odorevoked LFP oscillation reflects of a number of factors, including spiking of MTs, GABAergic synaptic currents, and population synchrony resulting from this inhibition. Regardless, oscillation power in the $\mathrm{OB}$ provides a functional measure of inhibition during odor responses, and pharmacologically altering the amount of inhibition mimics changes in oscillation power produced by D2Rs (Fig. 8B). Spontaneous as well as evoked LFP power is increased by D2R block (Fig. $8 C$ ), suggesting that a basal level of DA release is present in the $\mathrm{OB}$, constitutively reducing inhibition and directly affecting the net synaptic inputs received by MTs.

Modulation of inhibition in the OB potentially could alter MT tuning or intensity response characteristics. Duchamp-Viret et al. (1997) found that D2R activation reduced resting activity of MT units, also increased their threshold and latency for odor stimulation, and reduced spiking responses to weak stimuli. One possible role of the dopaminergic system may be to regulate olfactory sensitivity by altering MT excitability. Hyperpolarized cells will require greater sensory input to reach threshold, whereas reduced inhibition could compensate for reduced excitability, so responses of less excitable cells are not damped excessively. Several in vivo and behavioral experiments link DA to olfactory sensitivity. Naris occlusion decreases OB DA content (Baker et al., 1983; Brunjes et al., 1985) and increases the responsiveness of MT units, an effect that is mimicked by D2R block (Wilson and Sullivan, 1995). Odor detection also is impaired by systemic activation of D2Rs (Doty and Risser, 1989). A role in sensitivity is also consistent with the constitutive level of DA release seen here, which may set an intermediate level of $\mathrm{OB}$ excitability that then could be increased or decreased, depending on the needs of the system.

\section{References}

Alonso JR, Covenas R, Lara J, Arevalo R, De Leon M, Aijon J (1989) Tyrosine hydroxylase immunoreactivity in a subpopulation of granule cells in the olfactory bulb of teleost fish. Brain Behav Evol 34:318-324.

Aroniadou-Anderjaska V, Zhou F-M, Priest CA, Ennis M, Shipley MT (2000) Tonic and synaptically evoked presynaptic inhibition of sensory input to the rat olfactory bulb via $\mathrm{GABA}_{\mathrm{B}}$ heteroreceptors. J Neurophysiol 84:1194-1203.

Aungst JL, Heyward PM, Puche AC, Karnup SV, Hayar A, Szabo G, Shipley MT (2003) Centre-surround inhibition among olfactory bulb glomeruli. Nature 426:623-629.

Baker H, Kawano T, Margolis FL, Joh TH (1983) Transneuronal regulation of tyrosine hydroxylase expression in olfactory bulb of mouse and rat. J Neurosci 3:69-78.

Bazhenov M, Stopfer M, Rabinovich M, Abarbanel HD, Sejnowski TJ, Laurent G (2001) Model of cellular and network mechanisms for odorevoked temporal patterning in the locust antennal lobe. Neuron 30:569581.

Berkowicz DA, Trombley PQ (2000) Dopaminergic modulation at the olfactory nerve synapse. Brain Res 855:90-99.

Boyd JB, Delaney KR (2002) Tyrosine-hydroxylase-reactive interneurons in the olfactory bulb of the frogs Rana pipiens and Xenopus laevis. J Comp Neurol 454:42-57.

Brunjes PC, Smith-Crafts LK, McCarty R (1985) Unilateral odor deprivation: effects on the development of olfactory bulb catecholamines and behavior. Brain Res 354:1-6.

Buck LB (2000) The molecular architecture of odor and pheromone sensing in mammals. Cell 100:611-618.

Christie JM, Westbrook GL (2003) Regulation of backpropagating action potentials in mitral cell lateral dendrites by A-type potassium currents. J Neurophysiol 89:2466-2472.

Coronas V, Srivistava LK, Liang JJ, Jourdan F, Moyse E (1997) Identification and localization of dopamine receptor subtypes in rat olfactory mucosa and bulb: a combined in situ hybridization and ligand binding autoradiographic approach. J Chem Neuroanat 12:243-257.

Czesnik D, Rossler W, Kirchner F, Gennerich A, Schild D (2003) Neuronal representation of odourants in the olfactory bulb of Xenopus laevis tadpoles. Eur J Neurosci 17:113-118.

Davila NG, Blakemore LJ, Trombley PQ (2003) Dopamine modulates synaptic transmission between olfactory bulb neurons in culture. J Neurophysiol 90:395-404.

Debarbieux F, Audinat E, Charpak S (2003) Action potential propagation in dendrites of rat mitral cells in vivo. J Neurosci 23:5553-5560.

Delaney KR, Hall BJ (1996) An in vitro preparation of frog nose and brain for the study of odour-evoked oscillatory activity. J Neurosci Methods 68:193-202.

Dittman JS, Regehr WG (1996) Contributions of calcium-dependent and calcium-independent mechanisms to presynaptic inhibition at a cerebellar synapse. J Neurosci 16:1623-1633.

Doty RL, Risser JM (1989) Influence of the D-2 dopamine receptor agonist quinpirole on the odor detection performance of rats before and after spiperone administration. Psychopharmacology 98:310-315.

Duchamp-Viret P, Coronas V, Delaleu JC, Moyse E, Duchamp A (1997) Dopaminergic modulation of mitral cell activity in the frog olfactory bulb: a combined radioligand-electrophysiological study. Neuroscience 79:203-216.

Ennis M, Zhou FM, Ciombor KJ, Aroniadou-Anderjaska V, Hayar A, Borrelli E, Zimmer LA, Margolis F, Shipley MT (2001) Dopamine D2 receptormediated presynaptic inhibition of olfactory nerve terminals. J Neurophysiol 86:2986-2997.

Goldberg JH, Tamas G, Yuste R (2003) $\mathrm{Ca}^{2+}$ imaging of mouse neocortical interneurone dendrites: Ia-type $\mathrm{K}^{+}$channels control action potential backpropagation. J Physiol (Lond) 551:40-65.

Gonzalez A, Smeets WJ (1991) Comparative analysis of dopamine and tyrosine hydroxylase immunoreactivities in the brain of two amphibians, the anuran Rana ridibunda and the urodele Pleurodeles waltlii. J Comp Neurol 303:457-477.

Halasz N, Johansson O, Hokfelt T, Ljungdahl A, Goldstein M (1981) Immunohistochemical identification of two types of dopamine neuron in the rat olfactory bulb as seen by serial sectioning. J Neurocytol 10:251-259.

Halasz N, Nowycky MC, Shepherd GM (1983) Autoradiographic analysis of $\left[{ }^{3} \mathrm{H}\right]$ dopamine and $\left[{ }^{3} \mathrm{H}\right]$ dopa uptake in the turtle olfactory bulb. Neuroscience 8:705-715.

Hall BJ, Delaney KR (2002) Contribution of a calcium-activated non-specific conductance to NMDA receptor-mediated synaptic potentials in granule cells of the frog olfactory bulb. J Physiol (Lond) 543:P819-P834.

Hamilton KA, Kauer JS (1989) Patterns of intracellular potentials in salamander mitral/tufted cells in response to odor stimulation. J Neurophysiol 62:609-625.

Hoffman DA, Johnston D (1999) Neuromodulation of dendritic action potentials. J Neurophysiol 81:408-411.

Hoffman DA, Magee JC, Colbert CM, Johnston DJ (1997) $\mathrm{K}^{+}$channel regulation of signal propagation in dendrites of hippocampal pyramidal neurons. Nature 387:869-875.

Hsia AY, Vincent JD, Lledo PM (1999) Dopamine depresses synaptic inputs to the olfactory bulb. J Neurophysiol 82:1082-1085.

Huguenard JR, Coulter DA, Prince JR (1991) A fast transient potassium current in thalamic relay neurons: kinetics of activation and inactivation. J Neurophysiol 66:1304-1315.

Isaacson JS, Strowbridge BW (1998) Olfactory reciprocal synapses: dendritic signaling in the CNS. Neuron 20:749-761.

Jahr CE, Nicoll RA (1982) Noradrenergic modulation of dendrodendritic inhibition in the olfactory bulb. Nature 297:227-229.

Johnston D, Hoffman DA, Magee JC, Poolos NP, Watanabe S, Colbert CM, Migliore M (2000) Dendritic potassium channels in hippocampal pyramidal neurons. J Physiol (Lond) 525:75-81.

Kaba H, Hayashi Y, Higuchi T, Nakanishi S (1994) Induction of an olfactory memory by the activation of a metabotropic glutamate receptor. Science 265:262-264.

Kim K-M, Nakajima Y, Nakajima S (1995) G-protein-coupled inward rectifier modulated by dopamine agonists in cultured substantia nigra neurons. Neuroscience 69:1145-1158.

Kloppenburg P, Levini RM, Harris-Warrick RM (1999) Dopamine modulates two potassium currents and inhibits the intrinsic firing properties of 
an identified motor neuron in a central pattern generator network. J Neurophysiol 81:29-38.

Kosaka T, Hataguchi Y, Hama K, Nagatsu I, Wu YJ (1985) Coexistence of immunoreactivities for glutamate decarboxylase and tyrosine hydroxylase in some neurons in the periglomerular region of the rat main olfactory bulb: possible coexistence of gamma-aminobutyric acid (GABA) and dopamine. Brain Res 343:166-171.

Koster NL, Norman AB, Richtand NM, Nickell WT, Puche AC, Pixley SK, Shipley MT (1999) Olfactory receptor neurons express D2 dopamine receptors. J Comp Neurol 411:666-673.

Lacey MG, Mercuri NB, North RA (1987) Dopamine acts on D2 receptors to increase potassium conductance in neurones of the rat substantia nigra zona compacta. J Physiol (Lond) 392:397-416.

Lagier S, Carleton A, Lledo P-M (2004) Interplay between local GABAergic interneurons and relay neurons generates $\gamma$ oscillations in the rat olfactory bulb. J Neurosci 24:4382-4392.

Lowe G (2002) Inhibition of backpropagating action potentials in mitral cell secondary dendrites. J Neurophysiol 88:64-85.

Luo M, Katz LC (2001) Response correlation maps of neurons in the mammalian olfactory bulb. Neuron 32:1165-1179.

MacLeod K, Backer A, Laurent G (1998) Who reads temporal information contained across synchronized and oscillatory spike trains? Nature 395:693-698.

Margrie TW, Sakmann B, Urban NN (2001) Action potential propagation in mitral cell lateral dendrites is decremental and controls recurrent and lateral inhibition in the mammalian olfactory bulb. Proc Natl Acad Sci USA 98:319-324.

McLeod K, Laurent G (1996) Distinct mechanisms for synchronization and temporal patterning of odor-encoding neural assemblies. Science 274: 976-979.

Migliore M, Hoffman DA, Magee JC, Johnston D (1999) Role of an A-type $\mathrm{K}^{+}$conductance in the back-propagation of action potentials in the dendrites of hippocampal pyramidal neurons. J Comput Neurosci 7:5-15.

Momiyama T, Sim JA (1996) Modulation of inhibitory transmission by dopamine in rat basal forebrain nuclei: activation of presynaptic $\mathrm{D}_{1}$-like dopaminergic receptors. J Neurosci 16:7505-7512.

Mori K, Nowycky MC, Shepherd GM (1981) Analysis of synaptic potentials in mitral cells in the isolated turtle olfactory bulb. J Physiol (Lond) 314:295-309.

Mori K, Kishi K, Ojima H (1983) Distribution of dendrites of mitral, displaced mitral, tufted, and granule cells in the rabbit olfactory bulb. J Comp Neurol 219:339-355.

Nowycky MC, Mori K, Shepherd GM (1981) GABAergic mechanisms of dendrodendritic synapses in isolated turtle olfactory bulb. J Neurophysiol 46:639-648.

Nusser Z, Kay LM, Laurent G, Homanics GE, Mody I (2001) Disruption of $\mathrm{GABA}_{\mathrm{A}}$ receptors on GABAergic interneurons leads to increased oscillatory power in the olfactory bulb network. J Neurophysiol 86:2823-2833.

Palouzier-Paulignan B, Duchamp-Viret P, Hardy AB, Duchamp A (2002) $\mathrm{GABA}_{\mathrm{B}}$ receptor-mediated inhibition of mitral/tufted cell activity in the rat olfactory bulb: a whole-cell patch-clamp study in vitro. Neuroscience 111:241-250.

Rumsey JD, Darby-King A, Harley CW, McLean JH (2001) Infusion of the metabotropic receptor agonist, DCG-IV, into the main olfactory bulb induces olfactory preference learning in rat pups. Brain Res Dev Brain Res 128:177-179.
Sachse S, Galizia CG (2002) Role of inhibition for temporal and spatial odor representation in olfactory output neurons: a calcium imaging study. J Neurophysiol 87:1106-1117.

Schoppa NE, Westbrook GL (1999) Regulation of synaptic timing in the olfactory bulb by an A-type potassium current. Nat Neurosci 2:1041-1043.

Schoppa NE, Kinzie JM, Sahara Y, Segerson TP, Westbrook GL (1998) Dendrodendritic inhibition in the olfactory bulb is driven by NMDA receptors. J Neurosci 18:6790-6802.

Spruston N, Jaffe DB, Williams SH, Johnston D (1993) Voltage- and spaceclamp errors associated with the measurement of electrotonically remote synaptic events. J Neurophysiol 70:781-801.

Spruston N, Schiller Y, Stuart G, Sakmann B (1995) Activity-dependent action potential invasion and calcium influx into hippocampal CA1 dendrites. Science 268:297-300.

Stopfer M, Bhagavan S, Smith BH, Laurent G (1997) Impaired odour discrimination on desynchronization of odour-encoding neural assemblies. Nature 390:70-74.

Sullivan RM, Stackenwalt G, Nasr F, Lemon C, Wilson DA (2000) Association of an odor with activation of olfactory bulb noradrenergic $\beta$-receptors or locus coeruleus stimulation is sufficient to produce learned approach responses to that odor in neonatal rats. Behav Neurosci 114:957-962.

Svoboda K, Denk W, Kleinfeld D, Tank DW (1997) In vivo dendritic calcium dynamics in neocortical pyramidal neurons. Nature 385:161-165.

Tago H, Kimura H, Maeda T (1986) Visualization of detailed acetylcholinesterase fiber and neuron staining in rat brain by a sensitive histochemical procedure. J Histochem Cytochem 34:1431-1438.

Trombley PQ (1992) Norepinephrine inhibits calcium currents and EPSPs via a G-protein-coupled mechanism in olfactory bulb neurons. J Neurosci 12:3992-3998.

Tsubokawa H, Ross WN (1997) Muscarinic modulation of spike backpropagation in the apical dendrites of hippocampal CA1 pyramidal neurons. J Neurosci 17:5782-5791.

Wachowiak M, Cohen LB (1999) Presynaptic inhibition of primary olfactory afferents mediated by different mechanisms in lobster and turtle. J Neurosci 19:8808-8817.

Watanabe S, Hoffman DA, Migliore M, Johnston D (2002) Dendritic K ${ }^{+}$ channels contribute to spike-timing dependent long-term potentiation in hippocampal pyramidal neurons. Proc Natl Acad Sci USA 99:8366-8371.

Wilson DA, Sullivan RM (1991) Olfactory associative conditioning in infant rats with brain stimulation as reward: II. Norepinephrine mediates a specific component of the bulb response to reward. Behav Neurosci 105:843-849.

Wilson DA, Sullivan RM (1995) The D2 antagonist spiperone mimics the effects of olfactory deprivation on mitral/tufted cell odor response patterns. J Neurosci 15:5574-5581.

Wu L-G, Saggau P (1997) Presynaptic inhibition of elicited transmitter release. Trends Neurosci 20:204-212.

Xiong W, Chen WR (2002) Dynamic gating of spike propagation in the mitral cell lateral dendrites. Neuron 34:115-126.

Yokoi M, Mori K, Nakanishi S (1995) Refinement of odor molecule tuning by dendrodendritic synaptic inhibition in the olfactory bulb. Proc Natl Acad Sci USA 92:3371-3375. 